This item was submitted to Loughborough's Research Repository by the author.

Items in Figshare are protected by copyright, with all rights reserved, unless otherwise indicated.

\title{
Materialising social ontology
}

PLEASE CITE THE PUBLISHED VERSION

https://doi.org/10.1093/cje/bex038

PUBLISHER

Oxford University Press

VERSION

AM (Accepted Manuscript)

PUBLISHER STATEMENT

This is a pre-copyedited, author-produced version of an article accepted for publication in Cambridge Journal of Economics following peer review. The version of record ELDER-VASS, D., 2017. Materialising social ontology. Cambridge Journal of Economics, 41(5), pp. 1437-1451 is available online at: https://doi.org/10.1093/cje/bex038

\section{LICENCE}

CC BY-NC-ND 4.0

\section{REPOSITORY RECORD}

Elder-Vass, Dave. 2019. "Materialising Social Ontology”. figshare. https://hdl.handle.net/2134/25862. 


\title{
Materialising Social Ontology
}

\author{
Dave Elder-Vass*
}

This is a pre-publication version of a paper accepted for publication in the Cambridge Journal of Economics. It may differ slightly from the final published version. Please refer to the published version if citing.

\begin{abstract}
Social theorists increasingly recognise that material things often play vital roles in the causation of social events. However there is substantial disagreement on how to theorise these roles. Several members of the Cambridge Social Ontology Group have made important contributions in the form of their work on the ontology of technological objects. This paper builds on their work to develop an ontology of socio-technical structures: social entities composed of both humans and technological objects, with causal powers that depend on how these parts relate to, and interact with, each other. The implication is that material things are not just significant in their own right, or as parts of technical complexes, but that they can play a central role in social structures themselves. Indeed many of the most important and consequential social structures in contemporary societies, and in particular in contemporary economies, are socio-technical structures.
\end{abstract}

Keywords: materiality, social ontology, sociomateriality, socio-technical structures, technological objects

JEL classification: B50, O30

* Loughborough University. I would like to thank this journal's anonymous reviewers for their very helpful inputs to the development of the paper. 


\section{Introduction}

Like many other traditions of social science, realist accounts of social ontology have tended to neglect (though they have not entirely ignored) the causal role of non-human material objects in social events. People, institutions, social rules, social positions and social relations, for example, have received much more attention than material objects (Faulkner \& Runde, 2013b, p. 803). Several members of the Cambridge Social Ontology Group (CSOG), however, have paid welcome attention to one important class of ordinary objects - technological objects - and related them to some key issues in social ontology. While Tony Lawson himself has written relatively little on the topic, the work of his fellow CSOG members has developed, like his own, in the rambling but stimulating debates about basic concepts that are a feature of CSOG meetings and thus from a dialogical process in which he has played an important role.

This paper begins by describing and positioning some key features of these contributions, but its objective is to move beyond them to a different issue in social ontology: how to theorise the role that nonhuman material objects play in generating causal powers of social structures. For the purpose of social ontology we can define material objects as objects that consist of physical particles (Elder-Vass, 2015b), but human beings are also material objects, hence my use of nonhuman above. Given that the objects of concern are typically (and perhaps always) objects that have been assigned a function by human beings, we may also call these technological objects. ${ }^{1}$

While critical realists have paid a great deal of attention to social structure, they have largely ignored the possible role that material objects might play in it. On the other hand, theorists in some other traditions have discussed the social role of nonhuman objects but have tended to deny or marginalise the role of social structure. There is thus an absence in the literature: how can we theorise social structures that have nonhuman material objects as parts? The central theses of the paper are that (a) the vast majority of social structures, including those that are the greatest sources of social and economic power, are socio-technical structures, by which I mean entities composed of both human beings and technological objects; and (b) that we can best understand the major contribution that such structures make to causing social events through a critical realist ontology that examines the ways in which human and non-human parts interact to produce these larger structures and their powers.

The paper develops the argument in two main stages, interleaved with discussions of related developments in other areas of social theory. In the first stage, inspired on the one hand by the CSOG contributions discussed in the first section and on the other by the work of Georg Simmel, it considers entities that take the form of person-object dyads and the relation of their causal powers to those of the individuals and objects that are their parts. This provides enough material to compare the approach being developed here with recent theories of sociomateriality in organization studies. In the second stage, the paper considers more complex (though still somewhat stylised) social entities, in which multiple people and objects interact. This leads to a comparison of the critical realist approach proposed here with the more Deleuzian approaches of Latour and DeLanda. The paper concludes by considering the wider implications of the argument.

\section{Approaching materiality through technological objects}

Although my central concern is with non-human material objects in general and the roles they play in social structure, this set of referents overlaps heavily with what Clive Lawson, as well as Phil 
Faulkner and Jochen Runde, all CSOG members, have called "technological objects" (I employ Clive and Tony Lawson's forenames throughout to distinguish between them). For Faulkner and Runde, there are nonmaterial as well as material technological objects (Faulkner \& Runde, 2013b, p. 806), but I will confine my attention here to material technological objects (I will briefly discuss what we may call the semiotic dimension of material objects but this does not entail any recognition that there are such things as nonmaterial objects). Although there are differences of emphasis between Clive Lawson on the one hand, and Faulkner and Runde on the other, there is quite a bit of common ground between them, and they share a sophisticated sense of technological objects as simultaneously material and social. In this respect we may see their position as opposed to both more orthodox forms of realism and also more extreme forms of social constructionism.

According to Faulkner and Runde, more orthodox critical realists may see the nature and properties of a technological object as determined by its intrinsic structure - the sorts of parts it has and how they are organized or related to each other (Faulkner \& Runde, 2013b, p. 808, fn 6). Against this sort of position, and drawing on a more constructionist tradition of thinking about technology, both Clive Lawson and Faulkner and Runde take the view that technological objects depend on social positioning, and in particular on being positioned as having a particular function: "the use that members of some community impose on that object in pursuit of their practical interests" (Faulkner \& Runde, 2013b, p. 807). Thus, for example, "When a tree stump in the forest becomes a table it is because of the relationships in which it stands" (C. Lawson, 2010, p. 214). Technological objects, in other words, only become of use to us when we see them as such, and this in turn depends on them being enrolled in networks of relations with other objects, with their users, with their beliefs, and with their practices (C. Lawson, 2010, p. 213). Function, then, does not just depend on the physical capacities of an object but on their recognition and employment by a community of people. Employing an idea from Searle, Faulkner and Runde tell us that functions have to be "assigned by social groups whose members' activities contribute... to sustaining the function of the object concerned" (Faulkner \& Runde, 2009, p. 443). In one of his rare forays into this field, Tony Lawson has argued that "Social reality comprises in some part a multitude of inanimate objects, mostly humanly constructed as artefacts, that obtain social identities through being socially positioned" (T. Lawson, 2012, p. 376).

This insistence that function is an essential element in the identity of a technological object leads to one argument that may seem counterintuitive, and which I will come back to question shortly: the claim that when a technological object loses its function, in other words when there is no longer a community for whom it has that function, it ceases to 'be'. Clive Lawson, for example, using the case of a hammer, argues that

the form and content of the hammer would not disappear tomorrow if human societies ceased to exist (as say language would). But the hammer, in the eventuality of human societies ceasing to exist, would actually cease to be a hammer. Because part of what a hammer is exists only in relation to those using it (C. Lawson, 2007, p. 41).

As he says elsewhere, "what persists is the physical presence of the hammer, not it's being a hammer, which is of course a construction that would indeed disappear along with human societies" (C. Lawson, 2010, p. 214). 
A further implication is that the nature of a technological object can be transformed, without any material change in the object, by changes in the functions that are assigned to it. Faulkner and Runde support the point with the particularly engaging case of record turntables that have been transformed into musical instruments through "user innovations in function" - their employment by hip-hop DJ's in ways that were never intended or anticipated by their designers or manufacturers (Faulkner \& Runde, 2009).

Despite these somewhat constructionist arguments, the CSOG authors dissociate themselves from the more radical forms of social constructionism, which tend to focus only on the ways in which technological objects depend "on the attitudes and attributions of the communities in which they arise" (Faulkner \& Runde, 2013b, p. 810). We cannot make sense of technology through "a social constructivism that ultimately reduces technology to the social" (C. Lawson, 2007, p. 45), because "technical objects are constituted by natural as well as social mechanisms" (C. Lawson, 2007, p. 40). We cannot construct or position an object in any way we choose, or assign whatever function we like to it, because its potential functions are limited by the capacities it has, which depend in turn on its material form - what Clive Lawson calls its intrinsic powers (C. Lawson, 2010, p. 216). Thus they have not rejected but merely reframed the 'orthodox' approach of realists to objects: that their causal powers are produced by mechanisms which depend on the ways in which their parts interact, and on the ways in which those parts are organized in objects of this kind (Elder-Vass, 2010, Chapters 2-3). This fits well with several recent works that have advocated moderate versions of social constructionism and shown that they are compatible with critical realism (Elder-Vass, 2012; Sayer, 2000; Smith, 2010).

This is a "dual-nature conception of technology" (Faulkner \& Runde, 2013b, p. 807; see also Kroes, 2010 ) in which the nature or identity of a technological object depends both on its function, as discussed above, and its form. For material objects this concept of form aligns with my formulation above - to have a certain form is to have a certain set of material parts, organized in a certain way, that give the object "the capabilities required to perform that function" (Faulkner \& Runde, 2013b, p. 807). The re-positioning of the record turntable as a musical instrument illustrates the point nicely: it was only because the device had physical capabilities that could be re-purposed that new functions could be assigned to it, and only new functions compatible with those capabilities could be assigned. Although "form underdetermines function" (Faulkner \& Runde, 2009, p. 452) it does constrain it.

Although this is a coherent conception of technological objects, which will be built on later in this paper, I do have concerns about the argument that when a technological object like a hammer loses its function by virtue of the community concerned ceasing to exist, it ceases to be a hammer. The issue is most clearly approached by contrasting this case with a superficially similar one used by Tony Lawson (and frequently discussed in CSOG): the case of a large sea pebble being used as a paperweight (T. Lawson, 2012, p. 376). I suggest that a sea pebble does cease to be a paperweight when it is no longer used as one, but that a hammer does not cease to be a hammer when it loses the function of being used as one. The difference between the cases, however, is not ontological, nor does it arise from the pebble being found and the hammer being created. Rather, it is a linguistic difference between the ways in which these terms are commonly understood. The word pebble refers to a type of object that is defined by its physical properties; using the term loosely, we could say that it refers to a natural kind or to be less controversial a physical kind. The word paperweight 
refers to a type of object that is defined by its functional usage - anything that is used to hold down papers - and thus refers to a functional kind. Hence when a pebble ceases to be used as a paperweight it ceases to be a paperweight because it is no longer a member of the functional kind, but it remains a pebble because it is still a member of the physical kind.

The difficulty of the disappearing hammer arises because when we refer to technological objects we often use terms that refer to both dimensions at once. The word hammer refers to both a physical kind of objects (constructed in a certain way of certain sorts of parts) and a functional kind (objects that are used for hammering). For everyday practical purposes this works perfectly well as there is rarely any reason for us to distinguish between the two concepts. But in the context of a philosophical thought experiment that allows these two concepts to separate, identifying it with one at the expense of the other generates a puzzling outcome. When humanity ceases to exist and thus ceases to use hammers, then an actual hammer ceases to be a member of the functional kind and thus ceases to be a hammer in one sense of the word, but it remains a member of the physical kind and thus continues to be a hammer in the other. Because the actual word hammer is used to refer to both, it is misleading to say that hammers no longer exist.

One reviewer has suggested that this argument may not apply to technological objects like books, which also have a semiotic dimension, in the sense that when we refer to a book we mean the content of the book rather than the physical book. This certainly introduces further complexity, which I will return to below, but my argument still applies. The term book sometimes does refer to a physical object, e.g. when I say "please pass that book" and at other times to content, as when I say "that's a great book". When humanity ceases to exist some of the physical books may survive, but they will no longer have the functional significance that depends on there being a population capable of interpreting them as propositional content.

I make this argument because there is a danger that the case of the disappearing hammer may make the CSOG argument seem more constructionist than it actually is. A reader who took it out of context could be forgiven for thinking that it implies that physical objects are conjured into or out of existence by human intentions without any further physical process. But, whether or not they accept my linguistic modification, it is perfectly clear that Clive Lawson and Faulkner and Runde believe that the physical objects we currently call hammers continue to exist in this scenario, and therefore are committed to a thoroughly realist view of the causal processes at work.

Despite this quibble, the work of these authors is very important because it not only invokes both material and social factors in an account of technology, but also looks at the processes or mechanisms through which the two are related. This makes it possible to apply the argument to empirical cases: Clive Lawson has looked at the implications for how technology develops (C. Lawson, 2007), and Faulkner and Runde at the implications for user innovations in function (Faulkner \& Runde, 2009). Tony Lawson has invoked it more briefly in discussing how technological objects come to be used as status indicators and how this contributes to institutional reality in the sense employed by Searle (T. Lawson, 2012). Of these, the focus of this paper is closest to Tony Lawson's it examines the ways in which the capacities of technological objects are implicated in constituting larger social objects and generating their causal powers. 


\section{The object-person dyad}

Georg Simmel analysed the nature of sociality by starting from the case of two people interacting - a dyad - and building up his argument from there (Simmel, 1950, pp. 118-144). I propose to analyse the relationship between nonhuman material objects and human beings by starting from an equivalent dyad: the case of a single person interacting with a single technological object. Examples of such dyads might be a bicycle and rider, a DJ and turntable, or a writer and personal computer.

In such dyads, during those periods when the object is being used, the person and object interact, and those interactions depend upon a number of different types of causal capacity. First and second, they depend upon the causal capacities of the object itself, which it is useful in this context to divide into two types. First, we have features that a human being can employ to influence the behaviour of the object - and which we perceive as affordances, or possibilities for action provided by the object (Gibson, 1977). On a bicycle, for example, these control features usually include pedals, handlebars, and brake levers. Second, objects have other causal capacities, capacities that a human user may or may not be able to influence through its control features. Bicycles, for example, have the capacity to move rapidly along a smooth surface when suitably propelled by a human user pressing on the pedals, keeping the handlebars pointed in a suitable direction, and avoiding the use of the brake levers. According to the critical realist view, these capacities depend on the parts of the object, the relations between them, and processes of interaction between the parts that generate the causal powers of the object (for more details see Elder-Vass, 2010).

The remaining relevant capacities are capacities of the user. Third, the user has physical capacities, e.g. the capacity to push a pedal or pull a brake lever. Fourth, they have perceptual capacities, e.g. the capacity to sense the degree of resistance from the pedal and to see what is ahead and how their use of the control features is influencing the direction of travel. Fifth, they have knowledge of how to interact with the object, knowledge that may be accessed consciously and mentally, particularly for new users, or that may become habitual, embodied in muscle memory, and only indirectly subject to conscious control: most cyclists, for example, don't need to think about how to pedal. In the absence of user knowledge, the capacities of the object will go unused - Bonnington, for example, points out that many features of home energy systems are often unused because the human users are unaware of them (Bonnington, 2015). Sixth, they have the capacity to determine what to do with the object - which way, for example, to steer, and how fast to pedal. Seventh, they have knowledge of the social practices that have grown up around the object that regulate how they ought to use it, such as knowledge of which side of the road they should cycle on in the country where they are using the bicycle.

This list may not be complete, and it could be organized in other ways, but it is enough to make clear that a causal explanation of the use of an object will need to invoke the various elements identified by the CSOG authors in their account of the dual nature of technological objects. The form of the object determines its causal capacities, and the function of the object as understood in a community shapes the knowledge of users about how to use it and how it is appropriate to use it. These functional aspects are not, however, embodied in the object itself but rather are properties of a larger system of use that includes as a minimum the object and the user(s).

Thus we may say that both the object and the user have their own causal capacities, but many of these causal capacities are unused until the two parts of the dyad are brought together with each 
other. Once they are brought together, the combination of the two parts creates a new complex entity - the dyad - with emergent properties: properties that are not possessed by either part until and unless the two parts are combined in this way (on emergence see Bhaskar, 1975; Elder-Vass, 2010, Chapters 2-3; T. Lawson, 1997). Both DJ and turntable are required, for example, to produce the sorts of sound patterns that hip-hop DJs are famous for (Faulkner \& Runde, 2009).

A bicycle alone, or a turntable alone, cannot do any of the things that we find important in them. Their capacities cannot be activated without a user, and equally the user cannot achieve things that depend on the object until they combine with it. Clive Lawson, drawing on a long tradition in technology studies, has argued that one of the defining characteristics of technology is that it plays a role in extending human capabilities. He sees "technical activity as that activity that harnesses the intrinsic causal powers of material artefacts in order to extend human capabilities" (C. Lawson, 2010, p. 217). In the case of object-person dyads it does so by combining human beings with objects to form complexes with emergent causal capacities that extend beyond the capacities of unaugmented humans.

Clive Lawson also stresses, however, that these extensions depend on the enrolment of the objects concerned in networks of relations, both social and material (C. Lawson, 2010, p. 213). The powers of the cycle-rider dyad can only be realized in the context of interactions with further entities. On the material side, for example, effective cycling requires a reasonably smooth surface to cycle on, and so cycling depends on the causal capacities of roads and cycle paths. On the social side, effective cycling depends on a system of norms for road users, including country-specific norms about which side of the road to cycle on and more general norms that require other road users to avoid impacts with cyclists. This concept of enrolment, then, reflects the realist understanding of events as multiply determined: actual cases of cycling depend on the causal capacities of cyclists, the causal capacities of bicycles, the ways in which these are combined in cycle-rider dyads, the causal properties of roads, and the normative properties of communities, which all interact (and often with causal powers of other objects too) to produce and shape any actual case of cycling.

In the case of normative influences, these are most directly effective through their embodiment in the knowledge of the cyclist. Their embodiment in the user, however, depends on the user's prior and continuing exposure to influence from the wider community (in the form of norm circles: see Elder-Vass, 2010, Chapter 6). Japanese cyclists, for example, learn that they must cycle on the left side of the road, and this knowledge is embodied in them, but this knowledge represents the crystallization of a wider and continuing causal influence from the Japanese road using community in general. If Japan decided to switch overnight to driving and cycling on the right, and a cyclist was unaware of this, the wider community would continue to have a causal influence on her cycling practice. She might, for example, have to swerve to avoid unexpected oncoming traffic and one might expect that she would quite quickly adapt her sense of which side of the road to use.

\section{Sociomateriality}

Shortly I will build on this view of object-person dyads to develop an account of what I propose to call socio-technical structures. Elsewhere I have called these sociomaterial structures (Elder-Vass, 2016, p. 145), but the term sociomateriality (without the hyphen: see Orlikowski \& Scott, 2008, p. 456 ) is already in use in the organization theory literature, where some of its users have given it a sense that appears to conflict with the view of object-person dyads outlined above. 
The most prominent of these is Wanda Orlikowski. In one sense, Orlikowski is advancing an agenda that overlaps with the CSOG scholars discussed earlier, in that both are concerned to recognize the significant role played by technology in organisations and the social world more generally, and both are concerned by earlier neglect of that role (Faulkner \& Runde, 2013a, pp. 49-50; Mutch, 2013). As Orlikowski points out, "everyday organizing is inextricably bound up with materiality" (Orlikowski, 2007 , p. 1435) - at least in the sense that it always depends on a material context, the materiality of human beings, and usually on the employment of material artefacts - and this is frequently ignored in organization studies and indeed the social sciences more generally.

However, Orlikowski moves directly from this point to the claim that "the social and the material are constitutively entangled". This view does not "link them through a form of mutual reciprocation (in two-way interactions). Instead, the social and the material are considered to be inextricably related - there is no social that is not also material, and no material that is not also social" (Orlikowski, 2007, p. 1437). She distinguishes this from "Notions of mutuality or reciprocity [that] presume the influence of distinct interacting entities on each other, but presuppose some a priori independence of these entities from each other... In contrast, the notion of constitutive entanglement presumes that there are no independently existing entities with inherent characteristics... The distinction of humans and artifacts, on this view, is analytical only; these entities relationally entail or enact each other in practice" (Orlikowski, 2007, p. 1438). She goes on to cite John Law: "Materials - and so realities - are treated as relational products. They do not exist in and of themselves" (Orlikowski, 2007, p. 1438). ${ }^{2}$

As Faulkner and Runde and also Alistair Mutch have argued, this assumes a conflationist ontology in which different things become merged indistinguishably into each other, while we human observers make what Barad calls "agential cuts" (Faulkner \& Runde, 2013a, p. 59) to produce useful but ultimately misleading analytical distinctions which are not reflected in real separations (Faulkner \& Runde, 2013a, pp. 56-7; Mutch, 2013, p. 37). This conflation seems hard to square with the nature and operation of object-person dyads. Bicycles do exist independently of their riders, and riders do exist independently of their bicycles. Before someone buys or rents or borrows a bicycle, they both existed separately, independently and thoroughly extricably from each other. When I put away my bicycle at the end of the day and close the garage door on it, we become separate once more. As Faulkner and Runde put it, "most technological objects qua objects are separate from their users, in the sense that they do have structures that, once in existence, are often quite stable and do not depend on relations with particular users" (Faulkner \& Runde, 2013a, p. 57).

Bicycles, of course, do depend on human beings and social structures to come into existence in the first place, but this does not entail that they are inseparable in the sense that Orlikowski seems to be claiming. Moving from the causal dependence of bicycles on human beings for their creation, to the argument that they should not be treated as "separate (even if interacting) phenomena" (Orlikowski, 2007 , p. 1437) is a mistake that depends on a different sort of conflation - the conflation of diachronic processes of causality in the past with synchronic structures in the present. Those people who make bicycles neither become part of them nor become "constitutively entangled" with them, at least if constitutive is given its usual synchronic sense. Having said that, constitutive is a very slippery word, which is used to mean different things by different theorists, and sometimes to enable slippage between those different things (Elder-Vass, 2010, p. 141). But this does not alter the core issue: once a technological object has been created it has its own causal capacities, which at the 
time they are exercised depend only on what it is made of and how its parts are related to each other, irrespective of how it was made or by whom. There is no need to posit constitutive entanglement to explain those capacities.

Here it is worth returning to the case of objects with a semiotic dimension such as books, where the issues are a little more complex. Like a bicycle, the physical capacities of a book do not depend synchronically on human beings. Its pages continue to bear black letters on a white background whether there are people there to see them or not, and so those properties are not constitutively entangled with human beings. Also like a bicycle, the functional capacities of a book cannot be realised without a human being to make use of them, and so these capacities can only be exercised when the book interacts causally with a human being. The event of reading, and thus the creation of meaning in the reader, is a causal product of such interaction, and the content of the book exists only as a product of such interaction. It may therefore seem that there is a sense in which the semiotic dimension of an object like a book is constitutively entangled with human readers. However, propositional content itself is not a property of books as objects, but rather a property of their readers: the meaning of a book exists only in its reader's head and not in the book itself, though a physical book may have the causal capacity to prompt the generation of meaning in a suitably linguistically qualified reader (these issues are discussed in more depth in Archer \& ElderVass, 2012).

Nor are human beings constitutively entangled with technological objects, except in those cases where the objects really do become parts of the person. Orlikowski argues that "Humans are constituted through relations of materiality - bodies, clothes, food, devices, tools, which, in turn, are produced through human practices" (Orlikowski, 2007, p. 1438). In classic conflationist style, this sentence is a mélange of different issues. Humans are material objects, in the form of bodies, and this is one important sense in which materiality is fundamental to the social world. In the strict synchronic sense the material that makes up our bodies is constitutive of us. But that does not mean that other objects are constitutive of us. Clothes, tools, and devices are not constitutive of us, except those few devices that do become parts of us. My causal capacity to chew, for example, is partly a product of the dental fillings and crowns that have become parts of me. These really do contribute to my ongoing capacities. But most technological objects do not become parts of us in this way. Bicycles do not become parts of cyclists who ride them, and clothes do not become parts of the people who wear them (this assumes an ordinary language definition of part; for a more subtle discussion of the criteria of parthood, see (Elder-Vass, 2017). Throwing bodies together with objects that do not become parts of us in the same sentence merely confuses the issue (and of course the sentence also conflates the diachronic and the synchronic in the way I have criticized above).

Orlikowski also invokes a range of related traditions in recent science and technology studies to brand non-conflationist approaches as a kind of dualism. She wants us to speak "of the social and the material in the same register, and [... not revert] to a limiting dualism that treats them as separate (even if interacting) phenomena" (Orlikowski, 2007, p. 1437). The realist tradition, however, at least as I understand it, does speak of the social and material in the same register - both are seen as classes of entities with causal powers that influence events. Treating them in the same register, however, does not prevent us from recognising that individual social entities and individual non-social material entities are distinct from each other and can indeed interact. Orlikowski's argument here seems to perform yet another conflation: technology in the general sense clearly 
depends on social forces for its development, and the social world in a general sense clearly depends on the technology that it uses, but this is an entirely separate issue from the question of whether individual entities can be seen as distinct from each other.

Technological objects and human beings are not necessarily constitutively entangled. They do, however, interact causally with each other, and some of those causal interactions generate - we might even say constitute - larger entities with distinctive causal powers that depend on both the object(s) and the person(s). Object-person dyads are the simplest case, but things get more interesting still when we move onto more complex structures.

\section{Socio-technical structures}

Consider the case of two cyclists on a tandem. ${ }^{3}$ The tandem's structure and powers are analogous to the structure and powers of an ordinary bicycle. The riders' structures and powers are largely the same as those of any single cyclist. The relation between any given cyclist and the tandem is fairly similar to that of an ordinary cyclist to her bicycle. But by comparison with our cycle-rider dyad there is now a new relation that affects the behaviour of the triad as a whole: the relation between the two cyclists.

To be more precise, there are two different kinds of relation between the two cyclists. The first kind are spatial relations. These are similar in character to the relations between a single cyclist and her bicycle - for the cyclist to ride her bicycle she must adopt a particular spatial relation to it, and to influence its course she must make spatial movements that involve physical contact. Similarly, for two cyclists to ride a tandem together they must also adopt particular spatial relations to it.

But there is also a second, very different kind of relation that also now becomes important: intentional relations. These are relations that depend on the mental properties of the individuals concerned and in particular their intentional attitudes towards each other. For example, riding a tandem together is unlikely to work very well unless the two cyclists are cooperating, which means first of all that they must intend to cooperate, and second that they will need to communicate with each other and reach agreement on important decisions (or agree before setting off that the front rider or captain will take urgent decisions and the rear rider or stoker will follow suit). If the stoker would like to take the next left turn, for example, she will have to ask the captain to make it and persuade the captain to agree. The causal powers of the triad depend on these intentional relations, as well as on all the other elements discussed earlier. For example, the ability to achieve higher speeds depends on both riders agreeing to pedal hard at the same time.

Intentional relations of this sort are only possible in entities with multiple people as parts, and indeed they are the distinguishing feature of social entities (Elder-Vass, 2010, pp. 199-202). The set of social entities includes, for example, organizations, friendship groups and queues, and each of these has powers to affect events that depend on the intentional relations between the people who are parts of the entity concerned. Some of these entities, such as queues for example, may have only people as their parts, although the focus of this paper is those that have both people and nonhuman material objects as parts.

The addition of intentional relations is enormously important because it also makes possible two fundamental features of the social world. First, some social entities can be stretched loosely and diversely across space because their structures and powers do not depend on continuing and 
immediate physical contact or proximity between their human parts. A business that services equipment for widely distributed clients, for example, may have engineers at many different places, with their locations varying from hour to hour, and yet remain a coherent and causally effective socio-technical structure. Second, and for the same reason, people can be parts of multiple such entities at the same time. A bicycle can only be part of one object-person dyad at a time, and a wheel can only be part of one bicycle at a time, but a cyclist can be part of several different cycle clubs, as well as a family, a trade union, the business that employs her, and multiple other social entities all at the same time. Intentional relations are thus radically and importantly different from most object-object relations, and as a consequence social entities have kinds of properties that are not possessed by ordinary material objects.

Despite the importance of these intentional relations, a broad range of social entities also depend for their causal capacities on the contributions of their nonhuman material parts - on technological objects. Edwin Hutchins gives a nice example in his ethnographic investigation of the operation of the (pre-GPS) navigation system on a US naval ship (Hutchins, 1995). He shows how the process of navigation depends on a systematic set of interactions between a number of sailors adopting different roles and a number of pieces of equipment. Hutchins argues that collectively these sailors and this equipment form a system capable of plotting the ship's course. While he does not express the argument in terms of the critical realist ontology employed in this paper, this is clearly an example of a socio-technical entity with both human and nonhuman parts, with a causal power that depends on the full set of material/spatial and intentional relations discussed here. From a more philosophical perspective, and addressing the connections to critical realist ontology more comprehensively, I have applied the same model to the case of string quartets (Elder-Vass, 2017).

These entities are socio-technical structures. Socio-technical structures are entities with both people and technological objects as parts, and with causal powers that depend not only on the spatial relations and interactions between their human and non-human parts but also on the intentional relations and interactions between the different humans who are parts of the entity. In calling them this, I am on the one hand invoking an element of the earlier "socio-technical tradition, with its emphasis on a non-conflationary approach" cited by Mutch (2013, p. 29). On the other, I am a little cautious of the idea of treating social subsystems and technical subsystems as thoroughly distinct from each other (Leonardi, 2013, pp. 38-42; Mutch, 2013, p. 29). The point of my argument is that material things are not just socially significant as parts of distinctly technical subsystems but rather than they can and do play a central role in social structures themselves. The prevailing concepts of social structure in the social sciences, though diverse, have uniformly ignored the contributions of material objects but this radically misrepresents the ontology of the social world.

\section{Socio-technical structures and Deleuzian social theory}

While mainstream social science has often neglected material objects, various thinkers influenced by Gilles Deleuze have been arguing for the significance of material objects for some time now. This section argues briefly that critical realism offers a more promising route to accounting for the role of material objects in social structures.

The most influential of these thinkers is Bruno Latour, the leading figure in actor-network theory. Latour insists on the need to treat material objects on an equal basis with human beings when explaining social events (e.g. Latour, 1996, p. 57) and his work has played an important role in raising 
the profile of material objects in the social sciences (Elder-Vass, 2008). However, his work conflicts with the critical realist tradition in some quite fundamental ways (Elder-Vass, 2008, 2015a; Mutch, 2002; Vandenberghe, 2002). Two are particularly pertinent here.

First, Latour advocates a flat ontology that dispenses with social structure more or less entirely (Elder-Vass, 2008, pp. 463-6; Latour, 2005). In Latour's ontology, for example, individuals may think of organisations like the businesses that employ them as being causally significant, but Latour is only prepared to attribute significance to the other employees and objects that they interact with - to what I would call the parts of the business. What we need, however, is a structured ontology that shows how social structures depend on material objects but also have emergent powers of their own, powers that depend on the interactions between people and objects that occur only when such structures come into existence. Thus, for example, an army has causal powers that would not be possessed by the soldiers and weapons that are its parts if they were not organised into an army. A social ontology that includes soldiers and weapons but not armies misses out a crucial element for explaining what happens in military conflict. Hence the importance of recognising not only that material objects have a causal influence on social events but also that they can contribute to the causal powers of larger social wholes.

Second, Latour's ontology has no place for causal types. Events are brought about by interactions between assemblages, and not only is every event unique (as it is for critical realists) but every assemblage is also unique. He consistently rejects all attempts to classify assemblages into types and to assign consistency of causal influence to the members of a type. As Harman puts it, "For Latour an actant [and thus an assemblage] is always an event, and events are always completely specific: 'everything happens only once, and at one place'" (Harman 2009, 17) (the internal quote is from Latour 1993a, 162). But if we are to make sense of sociotechnical structures we must recognise that certain combinations of parts consistently produce certain causal mechanisms and powers.

Whenever we combine a competent cyclist and a working bicycle, for example, the resulting dyad consistently has the power to move much more quickly along a smooth road than either part would be able to alone.

Finally, let me briefly mention the work of Manuel DeLanda, who draws much more directly on Deleuze than Latour does, and also integrates elements of Bhaskar's early critical realism into his reading of Deleuze (Delanda, 2006, 2016). Unlike Latour, DeLanda recognises the existence of social entities with emergent causal powers (Delanda, 2006, p. 38, 2016, pp. 9-13). ${ }^{4}$ However, he remains at best ambivalent about the concept of causal types. He rejects the concept of essences (Delanda, 2016, pp. 139-43), although it is possible that the version he rejects is not the version that is usually associated with causal types. More generally, his ontology stresses the variability of assemblages within ranges characteristic of particular types rather than consistency within a type. Realists certainly do need to recognises variability within types but we must also be able to identify consistency within types, which is what underpins the causal mechanisms that generate consistent causal powers across multiple instances of the same type. DeLanda, then, is much closer to the position developed here, but the critical realist version of the argument remains both distinctive and more powerful. 


\section{Conclusion}

This paper has used a series of examples to illustrate the point that there are social entities - sociotechnical structures - that are composed of technological objects as well as people, and have causal powers that depend on both kinds of parts and their interactions with each other. The work of CSOG members on the dual nature of technological objects has made clear many of the relations between the material form of technological objects on the one hand and their use by humans on the other and enables us to piece together an account of how people and technological objects interact within such structures. This can then be combined with earlier realist work on the nature of intentional relations between human parts of social structures to give a more complex account of the nature of socio-technical structures.

There is perhaps a risk that the few scattered examples used here might leave the reader feeling that this is an interesting but marginal wrinkle on the surface of social ontology. Or perhaps it might seem to be of interest only to technology scholars. Nothing could be further from the case. The vast majority of social structures, including those that are the greatest sources of social power, are sociotechnical structures. The causal capacities of armies, for example, depend on their weaponry and not just their soldiers, the causal capacities of justice systems depend on prisons and not just police officers and judges, the causal capacities of the media depend on printing presses and web servers and not just on editors and journalists.

If there is one aspect of the social world where socio-technical structures are most strikingly dominant, it is the economy. Manufacturing concerns, retail organisations, transport and distribution networks, banks, and all of the vast range of economic undertakings that operate over the Internet (Elder-Vass, 2016, p. 145) are socio-technical structures. They all have both people and technological objects as their parts, generating causal powers that depend on both material/spatial and intentional relations between those parts. The entire economy is, in other words, a complex of socio-technical structures. Mainstream economics abstracts from all of this by reducing these relations to mathematical production functions, but in the process obscures much that is important about how the structures of the economy actually operate.

Tony Lawson and CSOG, by contrast, have dedicated themselves to uncovering the real structures of the economy. This is a long term project, and we will be building on their foundations for many years to come, but it is an essential part of the larger project of developing more plausible ways of explaining and challenging how our contemporary economy works.

\section{Notes}

1. Strictly speaking this paper is concerned with nonhuman material technological objects. Unlike Faulkner and Runde, I do not believe there are such things as immaterial technological objects and I do not consider it appropriate to include human beings in the class of technological objects (Faulkner \& Runde, 2013b).

2. Orlikowski's reference to Law gestures towards the more sophisticated conflationism of actornetwork theory which I have explained and critiqued elsewhere (Elder-Vass, 2015a). 
3. While we could add complexity to our dyads by considering cases where a single person interacts with multiple objects, this does not seem to raise significant further issues. It is not clear, for example, that the structure that emerges when a DJ interacts with not only a turntable but also a mixer and a set of speakers has very different ontological implications than structures that involve a single person and a single object.

4. Although Latour sometimes talks of new actants emerging, he uses emerge in the lay sense of something new appearing. This does not entail that this new things have causal powers in their own right that are dependent upon, but additional to, the properties of their parts. Certainly, he thinks that new actants influence events, but the part-whole emergence relation that is characteristic of both critical realism and DeLanda's thinking is thoroughly alien to Latour.

\section{References}

Archer, M. S., \& Elder-Vass, D. (2012). Cultural System or Norm Circles? An Exchange. European Journal of Social Theory, 15(1), 93-115.

Bhaskar, R. (1975). A realist theory of science (1st ed.). Leeds: Leeds Books.

Bonnington, O. (2015). The Indispensability of Reflexivity to Practice: The Case of Home Energy Efficiency. Journal of Critical Realism, 14(5), 461-484.

https://doi.org/10.1179/1572513815Y.0000000009

Delanda, M. (2006). A New Philosophy of Society: Assemblage Theory And Social Complexity.

London; New York: Continuum.

Delanda, M. (2016). Assemblage Theory. Edinburgh: Edinburgh University Press.

Elder-Vass, D. (2008). Searching for realism, structure and agency in actor network theory. British Journal of Sociology, 59(3), 455-73.

Elder-Vass, D. (2010). The Causal Power of Social Structures. Cambridge: Cambridge UP.

Elder-Vass, D. (2012). The Reality of Social Construction. Cambridge: Cambridge UP.

Elder-Vass, D. (2015a). Disassembling Actor-Network Theory. Philosophy of the Social Sciences, 45(1), $100-121$.

Elder-Vass, D. (2015b, November 4). Materialism and critical realism. Retrieved 14 June 2016, from http://materiallysocial.blogspot.com/2015/11/materialism.html

Elder-Vass, D. (2016). Profit and Gift in the Digital Economy. Cambridge: Cambridge UP. 
Elder-Vass, D. (2017). Material parts in social structures. Journal of Social Ontology, ahead of print.

Faulkner, P., \& Runde, J. (2009). On the identity of technological objects and user innovations in function. Academy of Management Review, 34(3), 442-462.

Faulkner, P., \& Runde, J. (2013a). On Sociomateriality. In P. M. Leonardi, B. A. Nardi, \& J. Kallinikos (Eds.), Materiality and Organizing: Social Interaction in a Technological World (pp. 49-66). Oxford: Oxford University Press, U.S.A.

Faulkner, P., \& Runde, J. (2013b). Technological Objects, Social Positions, and the Transformational Model of Social Activity. Management Information Systems Quarterly, 37(3), 803-818.

Gibson, J. J. (1977). The Theory of Affordances. In R. Shaw \& J. D. Bransford (Eds.), Perceiving, Acting and Knowing: Toward an Ecological Psychology (pp. 127-143). Hillsdale, NJ: John Wiley \& Sons Inc.

Hutchins, E. (1995). Cognition in the Wild. Cambridge, MA: MIT Press.

Kroes, P. (2010). Engineering and the dual nature of technical artefacts. Cambridge Journal of Economics, 34(1), 51-62. https://doi.org/10.1093/cje/bep019

Latour, B. (1996). Aramis: or the love of technology. Cambridge, MA: Harvard UP.

Latour, B. (2005). Reassembling the social. Oxford: Oxford University Press. Retrieved from http://www.loc.gov/catdir/enhancements/fy0635/2005296645-d.html

Lawson, C. (2007). Technology, technological determinism and the transformational model of social activity. In C. Lawson, J. Latsis, \& N. Martins (Eds.), Contributions to Social Ontology (pp. 3249). London: Routledge.

Lawson, C. (2010). Technology and the Extension of Human Capabilities. Journal for the Theory of Social Behaviour, 40(2), 207-223. https://doi.org/10.1111/j.1468-5914.2009.00428.x

Lawson, T. (1997). Economics and reality. London: Routledge.

Lawson, T. (2012). Ontology and the study of social reality: emergence, organisation, community, power, social relations, corporations, artefacts and money. Cambridge Journal of Economics, 36(2), 345-385. https://doi.org/10.1093/cje/ber050 
Leonardi, P. M. (2013). Materiality, Sociomateriality, and Socio-Technical Systems. In P. M. Leonardi, B. A. Nardi, \& J. Kallinikos (Eds.), Materiality and Organizing: Social Interaction in a Technological World (pp. 25-48). Oxford: Oxford University Press, U.S.A.

Mutch, A. (2002). Actors and Networks or Agents and Structures: Towards a Realist View of Information Systems. Organization, 9(3), 477-496.

Mutch, A. (2013). Sociomateriality - Taking the wrong turning? Information and Organization, 23(1), 28-40. https://doi.org/10.1016/j.infoandorg.2013.02.001

Orlikowski, W. J. (2007). Sociomaterial Practices: Exploring Technology at Work. Organization Studies, 28(9), 1435-1448. https://doi.org/10.1177/0170840607081138

Orlikowski, W. J., \& Scott, S. V. (2008). Sociomateriality: challenging the separation of technology, work and organization. The Academy of Management Annals, 2(1), 433-474.

Sayer, A. (2000). Realism and Social Science. London: Sage.

Simmel, G. (1950). The Sociology of Georg Simmel. New York: The Free Press.

Smith, C. (2010). What is a person? Chicago: University of Chicago Press.

Vandenberghe, F. (2002). Reconstructing humants. Theory, Culture \& Society, 19(5/6), 51-67. 